\title{
A study on the levels of depression, stress and anxiety of parents having children with intellectual disability
}

\author{
Sirisha Merla $^{1 *}$, S. Naveen Kumar ${ }^{2}$
}

\section{ABSTRACT}

Intellectual Disability is a developmental disorder characterized by significantly impaired intellectual and adaptive functions. Due to global developmental delay, persons with Intellectual Disability often are dependent on their parents/care takers and require high support and assistance for completing their self-help skills and other day to day activities. Role of Care Givers in context of globalization regarding care of Persons with Intellectual Disability and associated conditions is very critical and has placed diverse perspectives against life span needs. Parenting a child with intellectual disability brings a lot of change in psychological makeup of the parents, owing due to irreversible condition of the nature of intellectual disability. An attempt is made to understand whether parents of the child having intellectual disability are affected or not, if effected whether mother and father of the child are equally affected or not. The perception of the condition of child is perceived differently by mothers and fathers was taken for the study. Research was directed to understand the depression, stress and anxiety of parents having child with intellectual disability on mothers and fathers. A Comparative Study was undertaken to unearth the psychological makeup in parenting in terms of their depression, stress and anxiety levels that parents of intellectually disabled children have and comparison levels of those depression, stress and anxiety between mothers and fathers. A sample of 80 parents including 40 fathers and 40 mothers was randomly selected From Hyderabad, India. DASS21 scales was administered on these samples, Depression, Stress and Anxiety levels was measured in both mother and father of intellectually disabled children. Research Revealed that Parents both fathers and mothers of children with intellectual Disability experience significant level of Depression, Stress and Anxiety. Statistical Analysis on the results shows that there is no significant difference in Depression, Stress and Anxiety levels that mothers and fathers are subjected, Depression, Stress and Anxiety persistently existent in both female and male gender. Depression, Stress and Anxiety have an association, if one exists other two also exists in parents.

Keywords: Intellectual disabilities, parenting, Stress, Anxiety, Depression

${ }^{1}$ MA psychology, IGNOU, New Delhi, India

${ }^{2}$ M. Sc, MPhil, M.Ed., Guest Lecturer, NIEPID, Secunderabad, India

*Responding Author

Received: January 18, 2021; Revision Received: March 14, 2021; Accepted: March 23, 2021

(C) 2021, Merla S.\& Kumar S. N.; licensee IJIP. This is an Open Access Research distributed under the terms of the Creative Commons Attribution License (www.creativecommons.org/licenses/by/2.0), which permits unrestricted use, distribution, and reproduction in any Medium, provided the original work is properly cited. 


\section{A study on the levels of depression, stress and anxiety of parents having children with intellectual disability}

$\mathrm{I}$

ntellectual Disability is a developmental disorder characterized by significantly impaired intellectual and adaptive functions. Due to global developmental delay, persons with Intellectual Disability often are dependent on their parents/care takers and require high support and assistance for completing their self help skills and other day to day activities. Role of Care Givers in context of globalization regarding care of Persons with Intellectual Disability and associated conditions is very critical and has placed diverse perspectives against life span needs. Parenting a child with intellectual disability brings a lot of change in psychological makeup of the parents, owing due to irreversible condition of the nature of intellectual disability.

Intellectual disability is a state of functioning in which impairments to the central nervous system (CNS) (e.g., body functions and structures) result in activity limitations and participation restrictions. Specifically, CNS impairments manifesting in intellectual disability result in limitations to intellectual functioning (Schalock, R., Borthwick-Duffy et al. 2010).

Becoming a parent of a child with a disability can be a time of stress and change (Thompson, 2000). The diagnosis of a disability may disrupt the family system and require a new level of organization or balance (Burr, 1982; Patterson \& McCubbin, 1983). Some life events can be influenced and shaped by individuals. Having a child with a disability is an event that leaves many parents feeling they have little control; however, they do have significant control over how they react and cope with their situation (Rose, 1987).

Studies have shown an association between parental Depression, Stress and Anxiety in care taking of children with intellectual disability. In developing countries such as India concerning the impact of raising children with intellectual disability upon the quality of parent function.

In India, the majority of children with intellectually disability have traditionally been taken cared by their families. In today's modern society this home-based care has resulted in many adverse consequences. Factors such as changes in the social system (e.g. breaking up of joint families) and the economic system (e.g. unemployment, inflation, poor family economic conditions etc.) have contributed to Depression, Stress and Anxiety that parents of intellectually disabled children experience.

According to previous re-searchers parents of children diagnosed with Intellectual Disability consistently report more stress than parents of typically developing children (dyson,99, dolfnoh fisman, speechly-1989).

The pressure of raising an intellectually disabled child is an important concept in parenting and mostly it has a close relation with parents Depression, Anxiety and Stress. Taking care of children with special needs may leads to high level of negative emotions for the parents.

Therefore, the purpose of this research is

1. To Study the level of Depression, Stress and Anxiety in the parents who are rearing their intellectually disabled children.

2. Compare levels of Stress between mothers and fathers 


\section{METHODOLOGY}

The present study was conducted on patients of children have intellectual disability Hyderabad, in India. Nomothetic (Quantitative Approach) Psychology research method will be used for the study. The total sample consisted of 40 patients of children have intellectual disability i.e., 40 mothers and 40 fathers. For the purpose of our study, DASS21 Scale was administered upon patients of children have intellectual disability in individual situation and general instructions were given in the beginning of the test. The objective of the test was well explained to the parents before the administration. The parents of students studying in Preparna Special education school, Hyderabad, India and parents visiting National institute for the empowerment of persons with intellectual disabilities (Divyangjan), Secunderabad, India were selected for the study. Selection of parents was done with children having intellectual disability.

Sample size is 40 (i.e., >30) Hence z Test is more appropriate is use as statistical test. z values for Depression, Stress and Anxiety of both mothers and father data is calculated using Excel z test Data Analysis function.

NULL Hypothesis $\mathbf{H}_{0}$ : There is no significant difference between father and mother of children with Intellectual disability with respective Depression, Stress and Anxiety levels

\section{RESULTS}

Statistical Analysis The obtained data were analysed by applying zTest to find out the significance of difference between Depression, Stress and Anxiety of mother and father of children having intellectual disability.

Table 1. DASS21 Depression, Stress and Anxiety Statistical Data

\begin{tabular}{|c|c|c|c|c|c|c|c|c|}
\hline (2) & 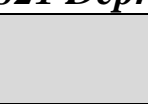 & $\mathbf{N}$ & Mean & SD & $\begin{array}{l}\text { Min. } \\
\text { Value }\end{array}$ & $\begin{array}{l}\text { Max. } \\
\text { Value }\end{array}$ & $\begin{array}{l}z \\
\text { Value }\end{array}$ & $\begin{array}{l}\mathbf{P} \\
\text { Value }\end{array}$ \\
\hline \multirow{2}{*}{ Depression } & Mother & 40 & 11.00 & 6.405 & 2 & 38 & \multirow[t]{2}{*}{0.8370} & \multirow{2}{*}{$\begin{array}{l}-0.206 \\
\mathrm{NS}\end{array}$} \\
\hline & Father & 40 & 11.30 & 6.649 & 2 & 34 & & \\
\hline \multirow{2}{*}{ Stress } & Mother & 40 & 12.90 & 8.063 & 0 & 30 & \multirow[t]{2}{*}{0.182} & \multirow{2}{*}{$\begin{array}{l}0.8552 \\
\text { NS }\end{array}$} \\
\hline & Father & 40 & 12.60 & 6.566 & 2 & 32 & & \\
\hline \multirow{2}{*}{ Anxiety } & Mother & 40 & 11.65 & 7.102 & 0 & 30 & \multirow[t]{2}{*}{1.526} & \multirow{2}{*}{$\begin{array}{l}0.1271 \\
\text { NS }\end{array}$} \\
\hline & Father & 40 & 09.60 & 4.667 & 0 & 20 & & \\
\hline
\end{tabular}

Level of Significance $=0.05 \quad$ Critical value $1.96 \quad$ NS- No Significant difference

From the sample data of DASS21 scale, mothers and fathers scores has been categorized in to levels as specified by DASS21 scale profile, below table shows percentage of parents that are in the category level. This data is depicted in pie diagram for easy understanding of the percentage distribution in the below figure.

Table 2 . DASS21 Depression, Stress and anxiety category percentage of parents

\begin{tabular}{|l|l|l|l|l|l|l|}
\hline & \multicolumn{3}{l}{$\begin{array}{l}\text { Mothers with Intellectually } \\
\text { Disabled child }\end{array}$} & \multicolumn{2}{l|}{$\begin{array}{l}\text { Fathers with Intellectually } \\
\text { Disabled child }\end{array}$} \\
\cline { 2 - 7 } & Depression & Stress & Anxiety & Depression & Stress & Anxiety \\
\hline Normal & $45.0 \%$ & $30.0 \%$ & $67.5 \%$ & $37.5 \%$ & $17.5 \%$ & $87.5 \%$ \\
\hline Mild & $22.5 \%$ & $10.0 \%$ & $12.5 \%$ & $30.0 \%$ & $10.0 \%$ & $10.0 \%$ \\
\hline Moderate & $25.0 \%$ & $25.0 \%$ & $17.5 \%$ & $25.0 \%$ & $42.5 \%$ & $2.5 \%$ \\
\hline Severe & $2.5 \%$ & $15.0 \%$ & $2.5 \%$ & $5.0 \%$ & $17.5 \%$ & $0.0 \%$ \\
\hline Extremely Severe & $5.0 \%$ & $20.0 \%$ & $0.0 \%$ & $2.5 \%$ & $12.5 \%$ & $0.0 \%$ \\
\hline & & & & & & \\
\hline Above Normal \% & $\mathbf{5 5 \%}$ & $\mathbf{7 0 \%}$ & $\mathbf{3 2 . 5 \%}$ & $\mathbf{6 2 . 5 \%}$ & $\mathbf{8 2 . 5 \%}$ & $\mathbf{1 2 . 5 \%}$ \\
\hline
\end{tabular}

(c) The International Journal of Indian Psychology, ISSN 2348-5396 (e) | ISSN: 2349-3429 (p) | 1002 


\section{A study on the levels of depression, stress and anxiety of parents having children with intellectual disability}

From the selected sample $62.5 \%$ of fathers have depression above Normal level while $55 \%$ for mother feels Depression above normal level, $82.5 \%$ fathers exposed to stress above normal level and $70 \%$ of mother exposed to Stress above normal level, Anxiety levels are quite different in mother and father, $32.5 \%$ of mother have anxiety above Normal level and $12.5 \%$ fathers have Anxiety above normal level. Extremely severe anxiety is not observed from both mother and father. Highest percentage of depression, stress and anxiety level that are above normal level are in Moderate category bother mothers and fathers. Compared with depression and Stress parents of intellectually disabled children are less anxious. Above $30 \%$ Parents both father and mother have stress level in sever and extremely severe.

\section{DISCUSSION}

The results on DASS21 depression have indicated that Null Hypotheses is not rejected in the light of statistical analysis which means there is no significant difference between mothers and fathers of children having intellectual disability with respective DASS21 Depression, the finding of the research is contradicting with Mohammadreza Bayat, et al, 2011 which said That there existed a significant difference between fathers and mothers as regards hostility behavior, depression, summarization inter personality senility and anxiety and obsessive-compulsive and there was no significant difference between fathers and mothers of intellectual disabilities children as regards psychotics, phobic and paranoid states. Since Depression is persistently existent with reference to the gender. As Depression is a state of low mood and aversion to activity that can affect a person's thoughts, behaviour, feelings, and sense of well-being.

The finding of the results of DASS21 stress states that Null Hypotheses is not rejected with statistical analysis which means there is no significant difference between mothers and fathers of children having intellectual disability with respective DASS21 Stress, the finding of the research is not consistence with (Raj Kumari Gupta, Harpreet Kaur 2010), as they reported insignificant differences in total stress and physical stress among mothers and fathers. However, they differ significantly in mental stress with mothers scoring higher and in contrast, Gerstein et al. (2009) found that parental stress in raising a child with a disability differs in mothers and fathers. Since is Stress persistently existent with reference to the gender, as Stress is an adaptive response to an external situation that results in physical, psychological and/or behavioral deviations for organizational participants.

The data analysis of the results of DASS21 anxiety states that Null Hypotheses is not rejected with statistical analysis which means there is no significant difference of anxiety between mothers and fathers of children having intellectual disability measure with DASS21, the finding of the research is not consistent with Mohammadreza Bayat, et al, 2011. Since is Anxiety persistently existent in both female and male gender, because Anxiety is a sudden onset of fear or distress that peaks in minutes when faced with problem or making an important decision.

\section{CONCLUSION}

The current study reveals that parents both mothers and fathers of children with Intellectual Disability experience significant levels of Depression, Stress and Anxiety. Statistical Analysis on the results shows that there is no significant difference in Depression, Stress and Anxiety levels that mothers and fathers are subjected. Depression, Stress and Anxiety persistently existent in both parents irrespective of their gender. But how ever there was a close association between Depression, Stress and Anxiety domains. 


\section{REFERENCES}

Abidin, R. R. (1995). Parenting Stress Index. Lutz, FL: Psychological Assessment Resources.

Akbar Husain and Osman Hashim Counselling to the Parents of Mentally Disabled, Counselling, Theory, Research and Practice, Published by Global Vision Publishing House

Amrita Sahay, Jai Prakash, Abdul Khaique, Priti Kumar, International Journal of Humanities and Social Science Invention;ISSN (Online): 2319 - 7722, ISSN (Print): 2319 7714; www.ijhssi.org Volume 2 Issue 7 || July. 2013\| PP.01-08

Ayrault, E.W. (2001). Beyond a Physical Disability. The Person Within - A Practical Guide. New York: The Continuum International Publishing Group.

Azar, M., \& Badr, L. K. (2006). The adaptation of mothers of children with intellectual disability in Lebanon. Journal of Transcultural Nursing, I 7(4), 375-380.

Baker, B. L., Blacher, 1., Crnic, K. A., \& Edelbrock, C. (2002). Behavior problems and parenting stress in families of three-year-old children with and without developmental delays. American Journal on Mental Retardation, 107(6), 433- 444.

Beckman, P. J. (1991). Comparison of mothers and fathers'perceptions of the effect of young children with and without disabilities. American Journal on Mental Retardation, 95(5), 585-595.

Ellis, N., Upton, D. \& Thompson, P. (2000). Epilepsy and the family: a review of current literature. Seizure, 9, 22-30.

McCubbin, H., and Patterson, J. 1982 "Family adaptation to crisis." Pp. 26-47 in H. McCubbin, E. A. Cauble, and J. Patterson (Eds.), Family Stress, Coping, and Social Support. Springfield, IL: Charles C. Thomas.

McCubbin, h. and Patterson, J. 1983 "Family stress and adaptation to crises: A Double ABCX Model of family behavior. Pp. 87-106 in D. Olson and B. Miller (Eds.), Family Studies Review Yearbook (Vol 1) Beverly Hills, CA: Sage Publications

Mohammadreza Bayat, Mahdieh Salehi, Abbolreza Bozorgnezhad and Akbar Asghari, 2011, The Comparison of Psychological Problems Between Parents of Intellectual Disabilities Children and Parents of Normal Children, World Applied Sciences Journal 12 (4): 471-475, 2011

Raj Kumari Gupta, Harpreet Kaur, 2010, Stress Among Parents Of Children With Intellectual Disability, Asia Pacific Disability Rehabilitation Journal, Vol.21 No.2 2010

Schalock, R., Borthwick-Duffy, S., Bradley, V., Buntinx, W., Coulter, D., Craig, E., et al. (2010). Intellectual disability: Definition, classification, and systems of support (11th ed.). Washington: American Association on Intellectual and Developmental Disabilities.

Seshadri M K. Verma S K, and Prashad(2000). Impact of mental retardation of child on the family in India. Journal of Clinical Psychology: 473-49

\section{Acknowledgement}

The author appreciates all those who participated in the study and helped to facilitate the research process.

\section{Conflict of Interest}

The author declared no conflict of interest. 
A study on the levels of depression, stress and anxiety of parents having children with intellectual disability

How to cite this article: Merla S.\& Kumar S. N. (2021). A study on the levels of depression, stress and anxiety of parents having children with intellectual disability. International Journal of Indian Psychology, 9(1), 1000-1005. DIP:18.01.104/20210901, DOI:10.25215/0901.104 